العمليات التحويرية في صخور تكوين خورمالة/ منطقة دوكان،

شمال شرقي العراق

$$
\text { قفوان فتحي اللهيبي علوم الأرض }
$$

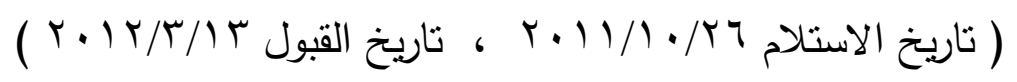

\title{
الملخص
}

تمت دراسة العمليات التحويرية في تكوين خورمالة الجيري (الباليوسين _ الايوسين المبكر) في قضاء دوكان _ شمال شرقي العراق، وقد أوضحت الدراسة نأثر صخور التكوين بالعمليات التحويرية التالية وهي ضمن تسلسل زمني متعاقب بدءاً بعملية المكرتة والدلمتة والاذابة والتتكل الجديد والسمنتة لتتنهي بعمليات

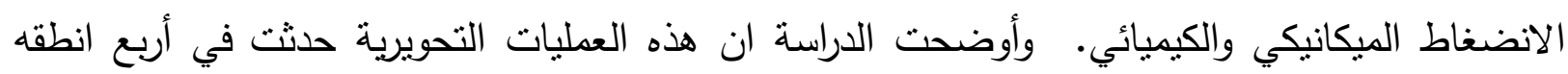

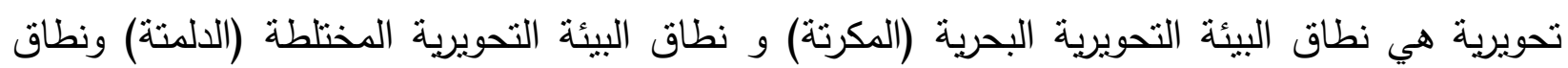

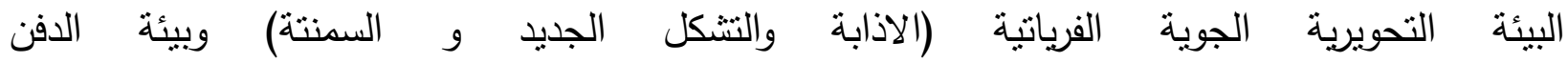

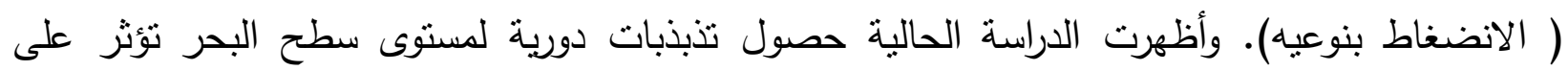
العطليات التحويرية وتسلسلها في رواسب التكوين في منطقة الدراسة.

\section{Diagenesis of Khurmala Formation in Dokan Area, \\ North Eastern Iraq}

\author{
Safwan F. Al-Lihaibi \\ Department of Geology \\ College of Science \\ University of Mosul
}

\section{ABSTRACT}

Diagenesis were studied within Khurmala limestone Formation at Dokan area, Northeastern Iraq. The study recognized many diagenetic processes affected limestone within a successive sequence including micrite envelope, dolomitization, dissolution, neomorphism, cementation, mechanical and chemical compaction. The study determined four diagenetic zones. They are marine zone 
(micrite envelope), mixing zone (dolomitization), meteoric pheratic zone (dissolution, neomorphism, cementation) and burial zone (mechanical and chemical compaction). According to the history of diagenesis and their sequence, the study revealed that periodical fluctuation in sea level has influenced on diagenetic processes and their paragenetic sequence.

\section{المقدمة}

تقع منطقة الدراسة التي ينكثف فيها تكوين خورمالة في قضاء دوكان شمال غرب مدينة السليمانية في شمال شرقي العراق، ضمن نطاق الطيات العالية (الثكل 1)، وقد وصف تكوين فئ خورمالة ( Khurmala) (Paleocene-L.Eocene) Formation

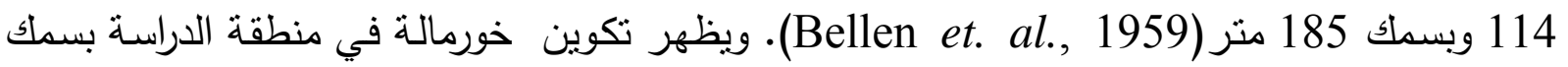

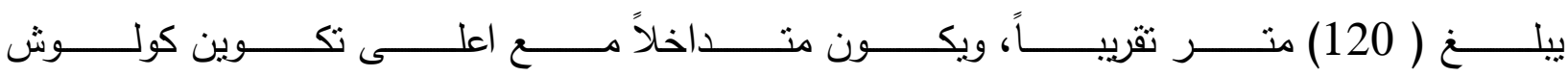

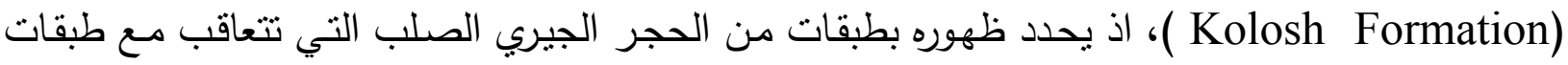

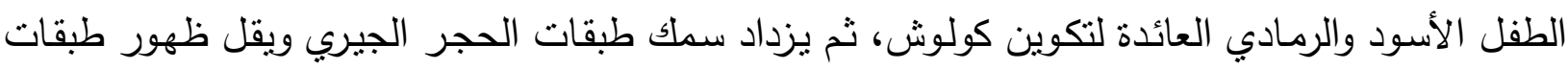
الطفل الأسود، ويتغير التعاقب إلى صخور الحجر الجيري المتدلدت وصخور الحجر الجيري المارلي والطفل

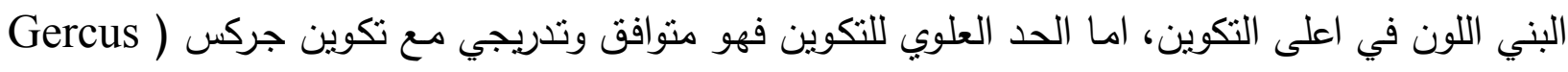
Formation

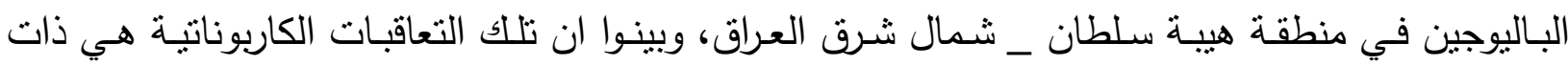

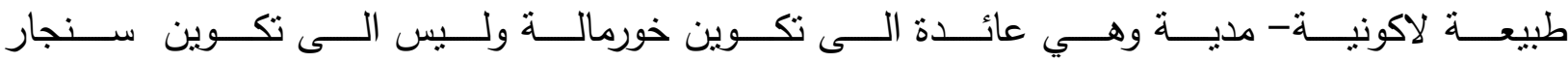
.( Sinjar ormation)

كما درس(Al-Qayim, 1995) السحنات الرسوبية لتكوين خورمالة في مقاطع مختارة في شمال العراق، ووجد ان هذا التكوين ترسب ضمن حزامين سحنيين، الاول هو حزام السحنات اللاكونية والثاني هو حزام سحنات مسطحات المد. وقد درس (الحميدي واخرون، 2011) نكوين خورمالة في منطقة دوكان وميزوا خمسة سحنات رئيسية دقيقة وهي: سحنة الحجر الجيري الطيني وسحنة الحجر الجيري الواكي وسحنة الحجر الجيري المرصوص وسحنة الحجر الجيري الحبيبي وسحنة الحجر الجيري المترابط واستتنجوا ان التكوين ترسب في ثلاثة انطقه بيئية وهي نطاق البيئة اللاكونية ونطاق المرتفع العضوي (Reef mound) ونطاق

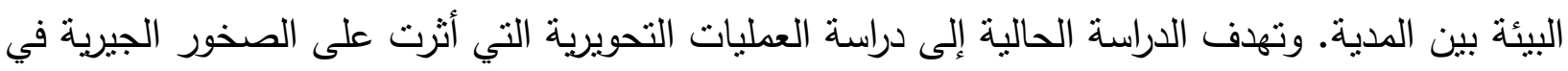
تكوين خورمالة في منطقة دوكان وتوضيح التسلسل الزمني لنتلك العطليات. 
العمليات التحويرية في صخور تكوين خورمالة / منطقة دوكان.

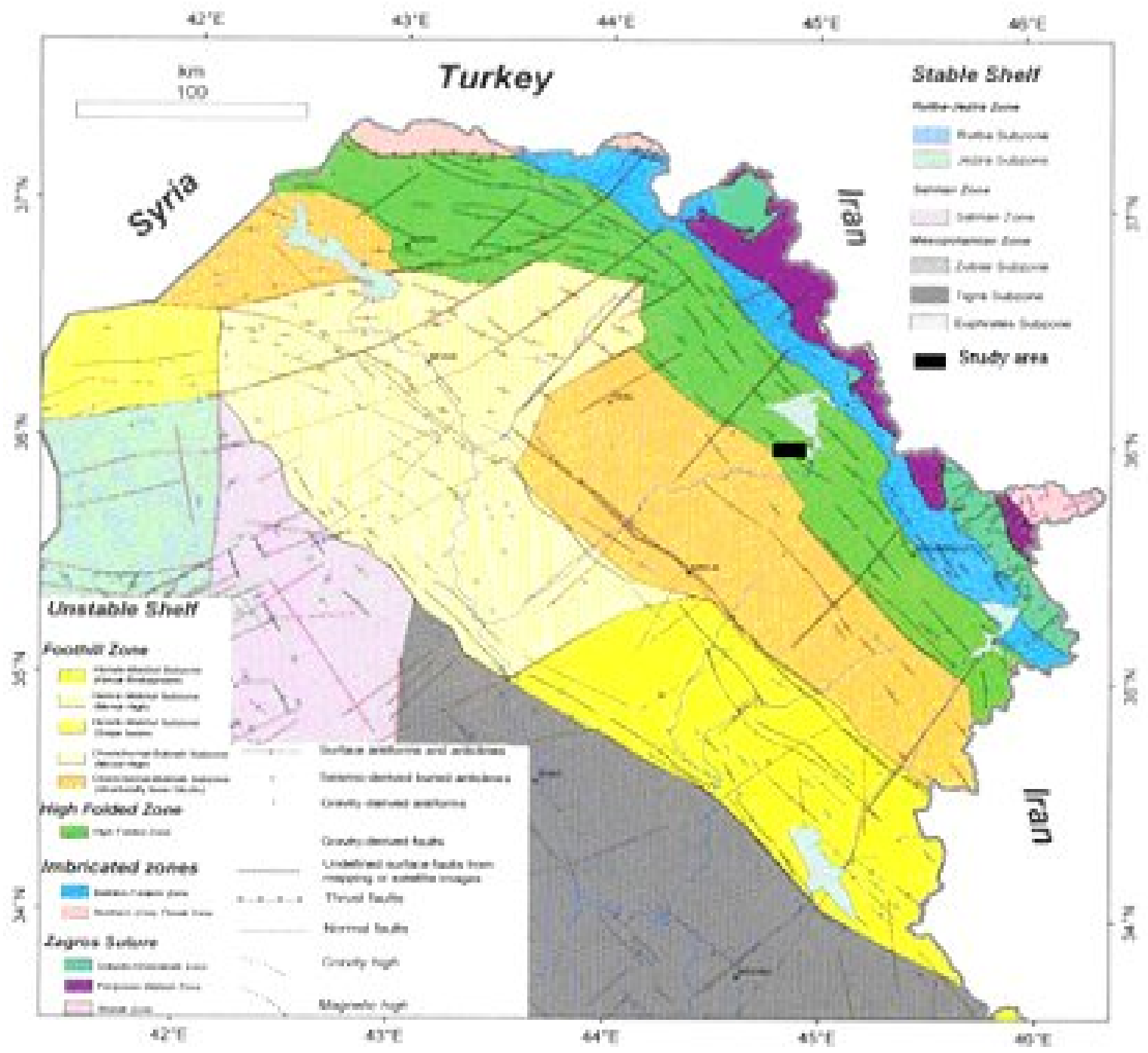

Buday and Jassim, 1984 in Jassim and ) الثنكل 1: يوضح خارطة العراق التكتونية عن (Goff, 2006 موضحاً عليها موقع منطقة الدراسة.

\section{الوصف البتروغرافي}

تتألف صخور التكوين بشكل عام من حبيات هيكلية (مثل المنخربات القاعية بأنواعها والنواعم والاوستراكود والطحالب الخضراء وشوكيات الجلا و البرايوزوا) والمكونات غير لهين الهيكلية

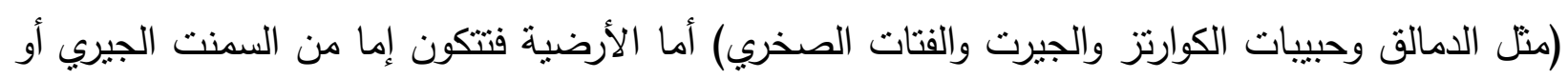
الطين الجيري. 


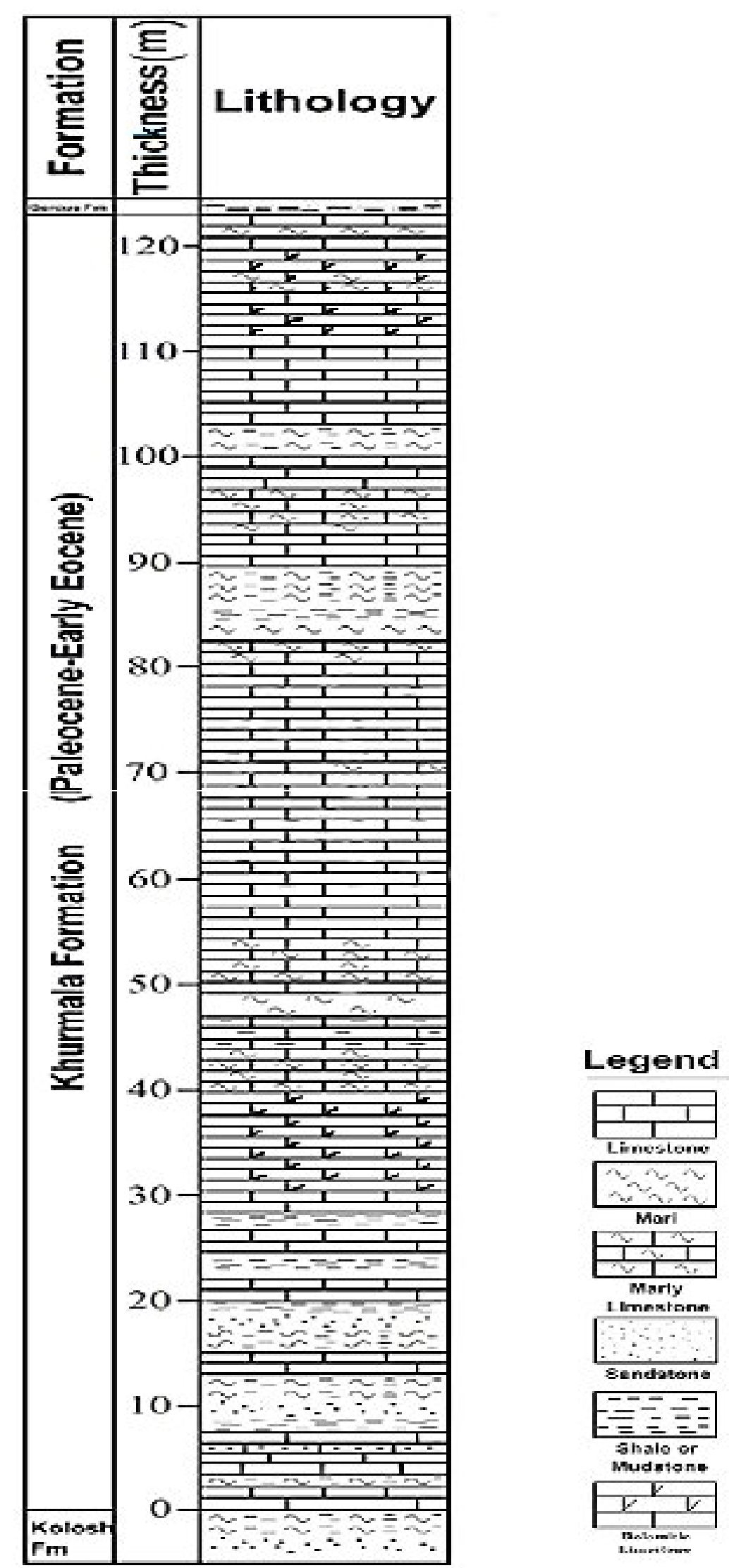

الشكل 2: يوضح العمود الرسوبي لتكوين خورمالة في منطقة الدراسة. 


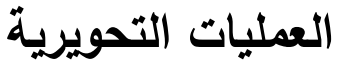

تتعرض الصخور الرسوبية من لحظة ترسييها إلى ما قبل تحولها إلى العديد من العمليات التحويرية

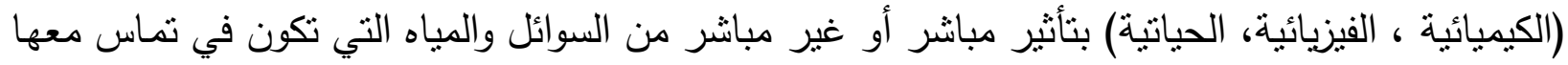

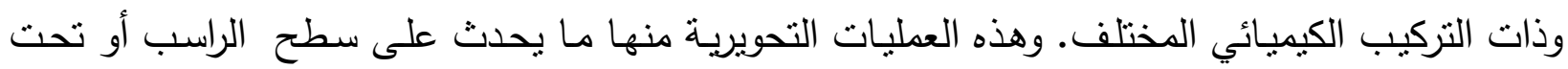
أعماق مختلفة (بعد الدفن)، تنواجد العمليات التحويرية في عموم تكوين خورمالة الجيري وترتبط العمليات

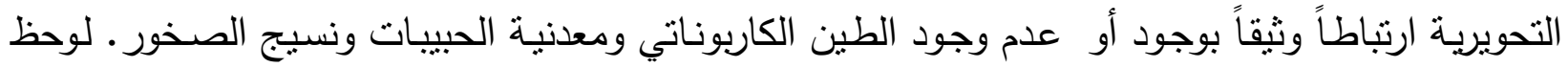
سبطرة السحنات على تواجد العمليات التحويرية. ويلعب كلاً من الزمن وطبيعة الدحاليل وكيميائيتها دوراً كبيراً في تسلسل العطليات التحويرية في صخور التكوين.

وقد تعرضت صخور الدراسة الحالية الى العديد من العمليات التحويرية من أبرزها:

\section{Micritic Envelope الغلاف المكريتي -A}

سجلت هذه العملية التحويرية المبكرة في العديد من سحنات التكوين خصوصاً في سحنات ذات الدعم الحبيبي، حيث يظهر الغلاف المكرايتي محيطاً بالعديد من الأصداف خصوصاً أصداف المنخربات القاعية مثل المليوليود، وهذا الغلاف المكرايتي عبارة عن بلورات كاربونات الكالسيوم دقيقة التبلور ، حيث المعدن

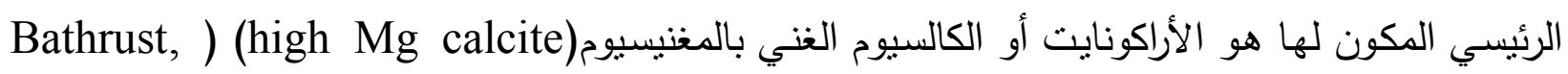
. $(1975$

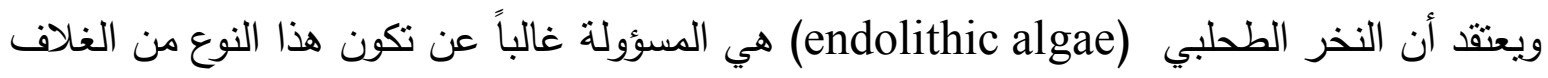

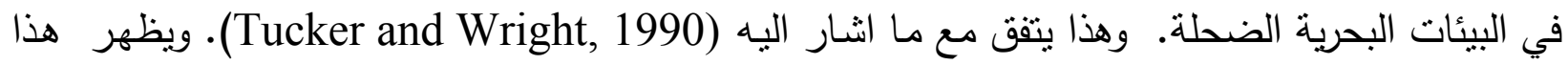

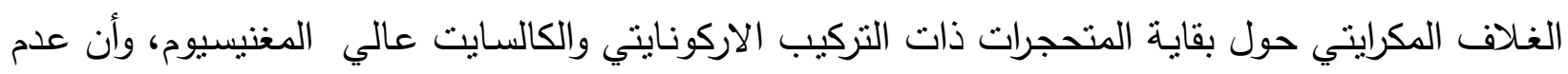

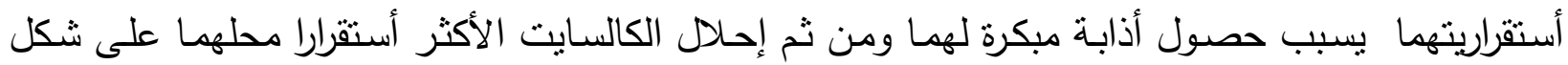
سمنت، فيما يحافظ الغلاف المكرايتي على الثكل الخارجي للحبيبات الكاربوناتية (هياكل الأصداف) (لوحة الونة

\section{Dolomitization الالمتة -B}

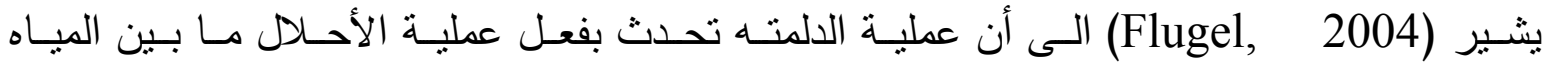

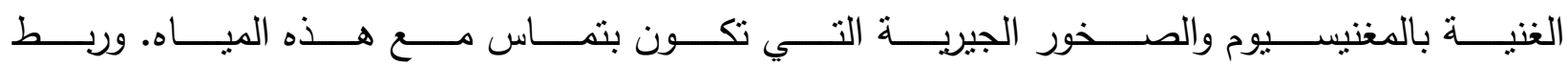
ما بين الدالة الحامضية القلوية والحرارة العالية مع وجود تجهيز (Machel and Mountjoy, 1987)

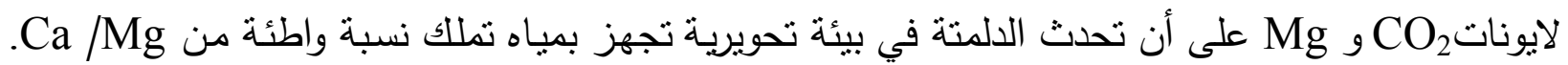

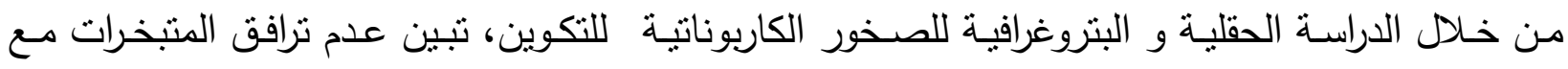


الصخور الكاربوناتية، وذلك لعدم وصول تركيز الأملاح إلى مرحلة الإثباع اللازم لترسيب المتبخرات لوجود

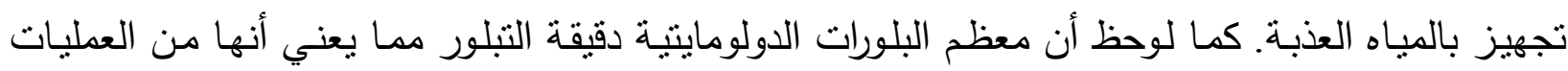
التحويرية المبكرة. ولقد أثنار كل من(Hsu and Siegenthaler, 1969) و (Tucker, 1985) إلى أن هذاه النوع من العمليات التحويرية مدكن حدوثه في مناطق المسطحات التحت مدية والبين مديـة خصوصاً في فترات التراجع البحري.

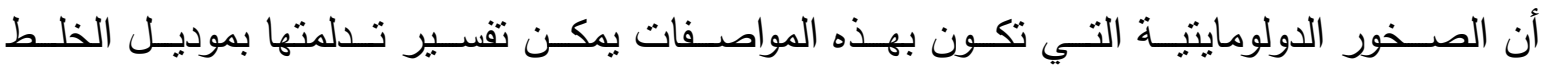
(الموضوع من قبل (Badiozamani, 1973) والتي تتطلب امتزاج مياه كونية عذبة فئة (Mixing Zone) (Meteoric Water)

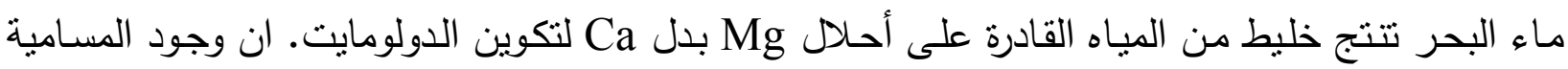

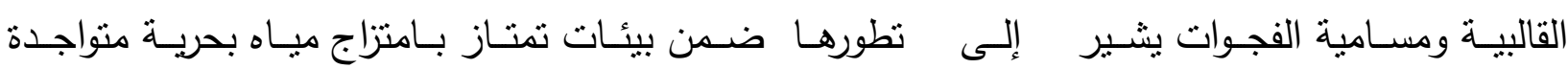

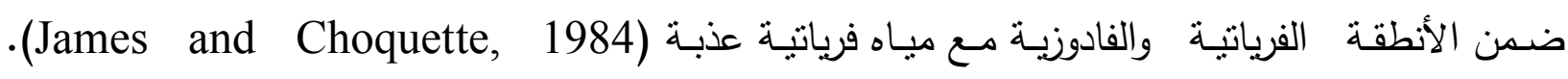

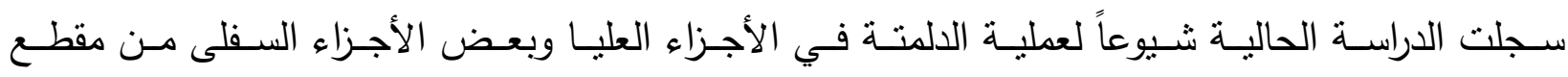

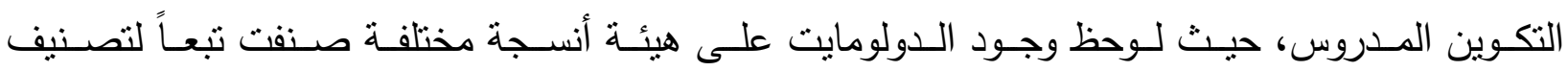
Randazzo and Zachos, 1984)

\section{1- النسيج الدقيق التحبب Aphanotopic Texture}

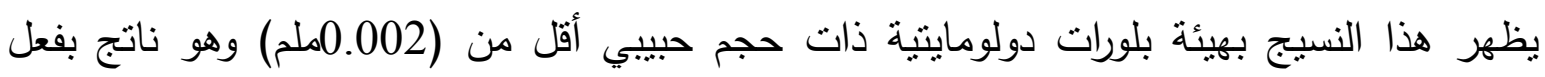
الدلمتة المتجانسة للصخور الحجر الجيري الطيني (Randazzo and Zachos, 1984). وتثشير الصفات النسيجية لهذا النوع من الدولومايت والتي يصعب تمييز حدودها البلورية الى تكونها في المراحل المبكرة من

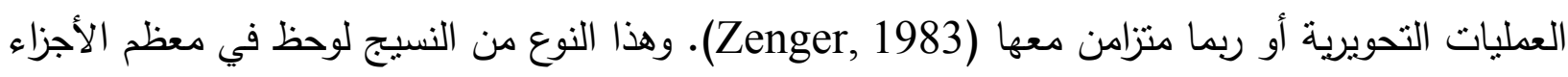
العليا من مقطع الدراسة(لوحة-B-1).

Suture Mosaic Texture النسيج الموزائيكي الارزي شخص هذا النوع من النسيج في أعلى الأجزاء السفلى من مقطع التكوين المدروس حيث تثتكل

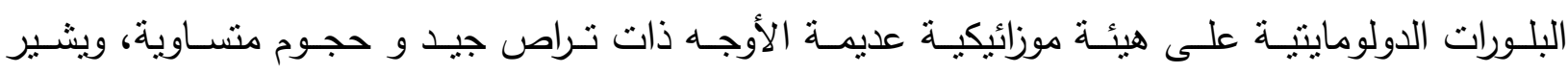
(Randazzo and Zachos, 1984) الجيري(لوحة C-C). 


\section{3- النسيج الموزائيكي المنظلي Sieve Mosaic Texture}

لوحظ هذا النوع من النسيج في العديد من أجزاء المقطع السفلى والعليا حيث نكون بلورات الدولومايت

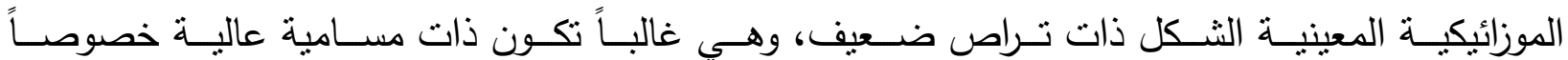

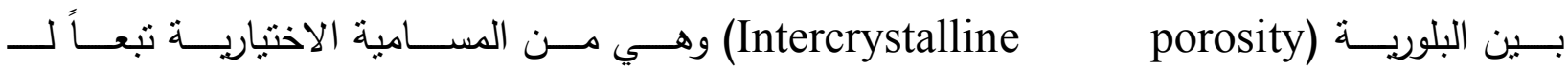
(Choquatte and Pray, 1970) حيث تظهر المسامية في المناطق التي تسود فيها بلورات الدولومايت

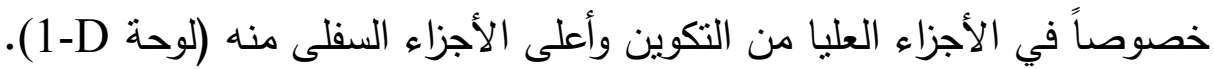

\section{Dissolution الإذابـة -C}

هي عملية إذابة المعادن غير المستثرة بفعل المحاليل المؤثرة على الصخور، اذ يشير (Milliman, 1974) بهذه الحبيبات بجذر الكاربونايت فضلاً عن عوامل الحرارة والضغط وضغط لعت لعد أهم العوامل المؤثرة

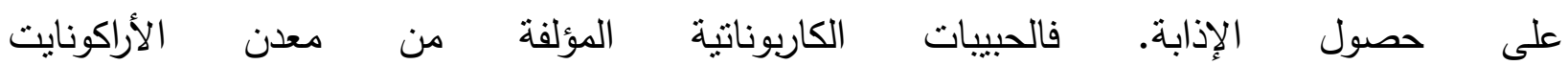
( قليل الاستقرارية ) أو المؤلفة من الكالسايت الغني بالمغنيسيوم تتعرض للإذابة بدرجات متفاوتة بالمقارنة مع الحبيبات الكاربوناتية المؤلفة من الكالسايت الفقير بالمغنيسيوم (Low Mg calcite) الأكثر أستقرارية، فيؤدي أحياناً إلى إزالة أصداف المتحجرات ناركاً موضعها فارغاً، وفي حال نأثرها بعملية تكوين الغلاف المكرايتي فأن الأجزاء الداخلية تذوب وييقى الهيكل الخارجي ذو الغلاف المكرايتي غير ذائب بسبب مقاومته لعملية الإذابة (لوحةE-1). كما يلاحظ عدم تأثر أصداف الدحاريات (Oyster)(لوحة F-1-) بهذه العملية بسبب كونها مؤلفة من الكالسايت الفقير بالمغنيسيوم.وتتتج عن عملية الإذابة ما يعرف بالمسامية ،وهذه المسامية تكون باشكال مختلفة وذلك بسبب عدم تجانس الصخور الكاربوناتية.

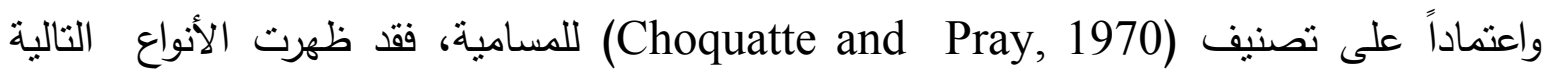
للمسامية الثانوية الناتجة عن الاذابة:

\section{1- مسامية الفجوات (Vugy porosity):}

هذه النوعية من المسامية هي مسامية غير اختيارية، حيث تظهر فراغات الإذابة هنا بصورة غير منتظمة الثكل (لوحة G-G) ويعتقد أنها تشكلت بفعل إذابة الحبيبات ومن ثم تشوهت بفعل استمرار فعالية محاليل الإذابة خلال هذه الفراغات. 
2- المسامية القالبية (Moldic porosity): تقوم محاليل الإذابة بإذابة الأصداف الأراكونايتية أو الكالسايتية الغنية بالمغنيسيوم أو أي حبيبات

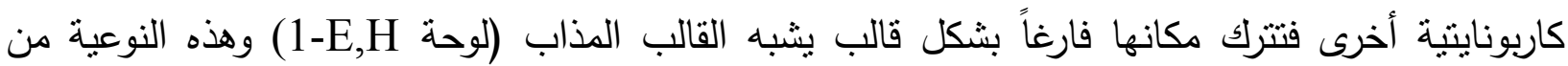
المسامية تعود إلى المسامية الاختبارية.

\section{Neomorphism التشكل الجديد -D}

في أطار الدراسة الحالية أمكن التعرف على عملية التشكل الجديد بنوعيها الأرتكاس (Inversion) تتضمن تغيرات حجمية لبلورات من دون حدوث تغيرات في التركيب المعدني أو الكيميائي. فمن خلال

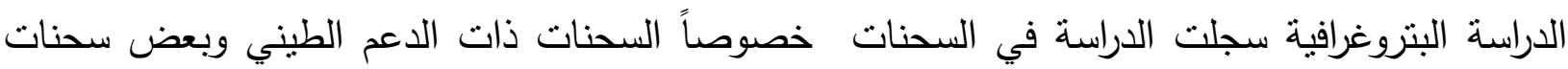
الدعم الحبيبي حدوث عملية أعادة تبلور المكرايت إلى السبار الدقيق (Microspar) (لوحةه-A (2) والسبار الكاذب (Psudospar) (لوحة3-B)، وهي من عمليات التثكل الجديد البنائية كما أثنار إلى ذللك العديد من الباحثين منهم (Boggs, 2006; Flugel, 2004; Bathurst, 1975). كما سجلت الدراسة عملية الأرتكاس وكان ذلك واضحاً من خلال تحول أصداف المتحجرات خصوصاً فأسية القدم (Pelecypod) وبطنيه القدم (Gastropod) ذات الجدار الأراكونايتي الأقل استقرارا إلى بلورات موزائيكية من الكالسايت

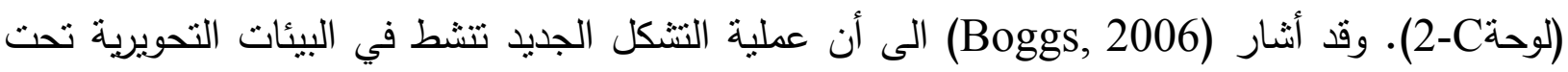
سطحية المتأثرة بالمياه الجوية.

\section{Cementation السمنتة}

وهي عملية ترسيب الكالسايت السباري (Spary calcite) داخل هياكل بعض المتحجرات التي يكون

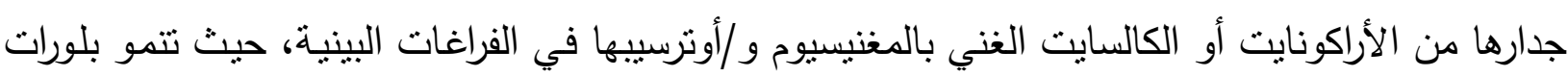

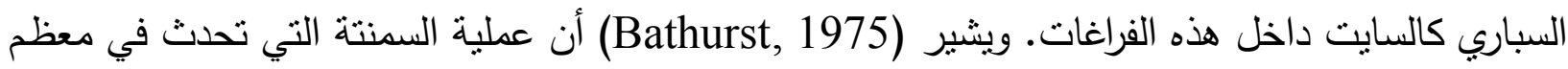

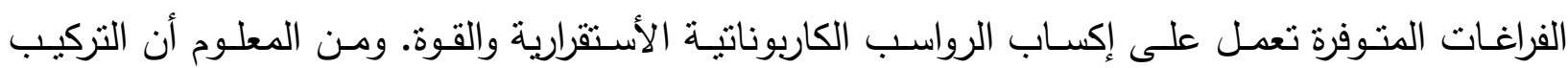

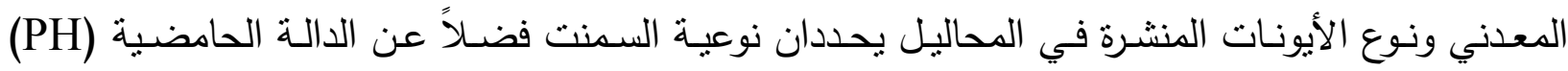
والحرارة وضغط Longman, 1980) CO في نماذج الدراسة الحاليةوهي: 
Drusy Cement السمنت الاروزي يتشكل هذا النوع من السمنت غالباً في السحنات ذات الدعم الحبيبي في نماذج الدراسة، حيث أنه

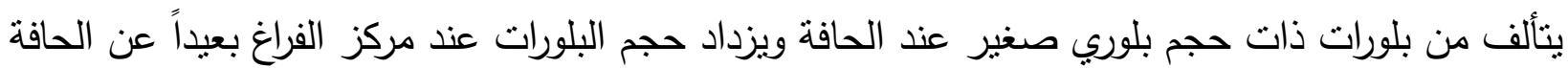

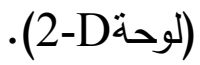

يشير (Flugel, 2004) الى أن هذا النوع من السمنت يحدث ضمن الأنطقة الفادوزية والفرياتية ذات المياه العذبة، واعتقد انه تكون ضمن نطاق المياه العذبة الفرياتية وذلك لعدم وجود أي دليل على البيئة التحويرية الفادوزية، مثل وجود السمنت الهلالي (meniscus) والسمنت الهدبي ( acicular)والسمنت الفياه المعلق (pendant).

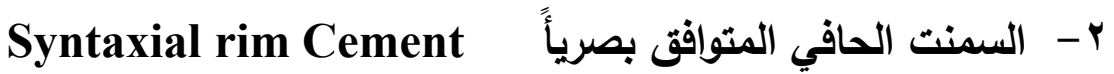
تتمو بلورات الكالسايت السمنتية على هيئة مستمرة بصرياً وينتشر غالباً على شكل سمنت نامي حول أصداف شوكيات الجلد (لوحةE-2). هذا النوع من السمنت يحدث في بيئة متأثرة بالمياه الجوية، ولوحظ بئه تواجد هذه النوعية من السمنت في قليل من السحنات، وهذا النوع من السمنت تكون ضمن البيئة الفرياتية الجوية وهذا يتفق مع ما اشار اليه ( Longman,1980) حول تشكل هذا النوع من السمنت.

\section{Granular Cement} $-3$

تمتاز البلورات السمنتية في هذا النوع من السمنت بكونها موزائيكية شبه كاملة الأوجه متساوية الحجوم تقريباً (لوحةA-1). وينكون هذا النوع من البلورات السمنتية في الفراغات البينية. ويشير (Flugel, 2004)

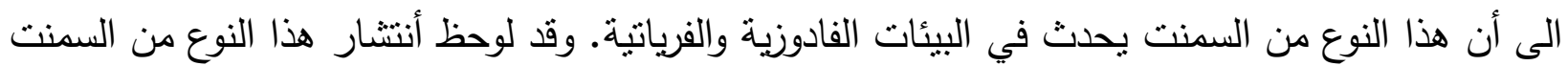

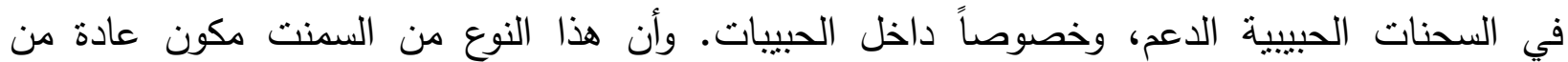
Longman, (الكالسايت الفقبر بالمغنيسيوم والذي قد تكون ضمن البيئة الجوية وهذا يتفق معا ما اثنار اليه من اليه

\section{Mechanical Compaction الانضغاط الميكانيكي -F}

تؤدي عملية الانضغاط الميكانيكي إلى تقليص الحجم الكلي للترسبات وتشويه شكلها الخارجي بفعل وزن الترسبات الفوقية، وتعمل أيضاً على تثويه الحبييات وتراصها وإعادة ترتيبها. وبالإمكان ملاحظة تأثير

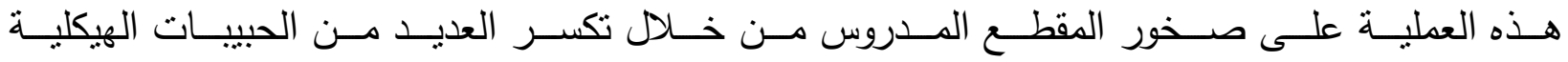
(2-Fتمنل فاسية القدم) (لوحساً في سحنات الدعم الحبيبي وتعتبر هذه دليل على بيئة دفن تحويريه

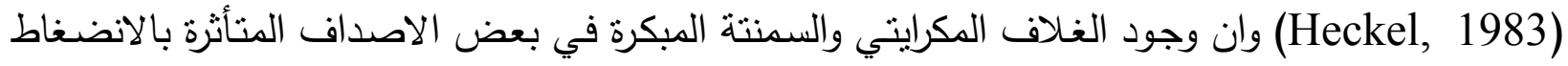


يعطي دلبلاً على حدوث التكسرات بفعل الانضغاط الميكانيكي وليس بفعل الطاقة الهايدروديناميكية والتي يمكن الاستدلال عليها بعدم وجود القطع الحياتية. كما أدت عملية الانضغاط الميكانيكي الى ظهور مسامية الكسور • وقد سجلت الدراسة الحالية أنتشاراً

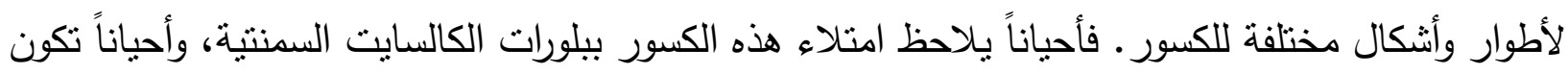

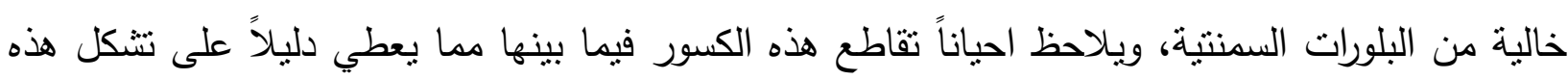

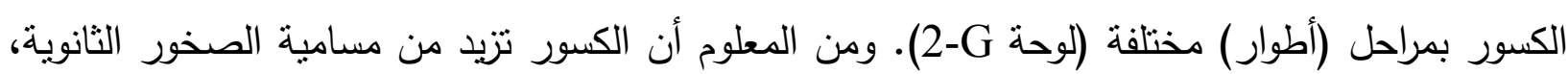

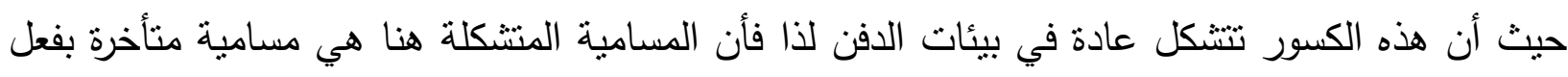

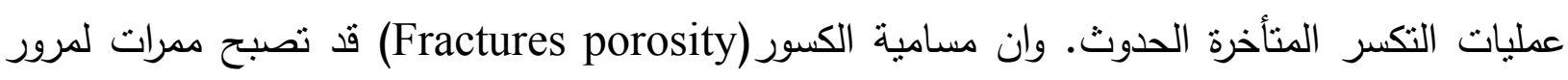
محاليل الأذابة فتعمل على توسيعها. أن وجود أنواع مختلفة من الكسور والعروق يعطي دلالة واضحة فلعه على تعرض هذه الصخور الى إجهادات تكتونية مختلفة فضلاً عن تعرضها الى إجهادات التقل الرسوبي بمراحل مختلفة.

\section{Chemical Compaction}

-G

ينتج هذا النوع من الأنضغاط عن إذابة نقاط التماس مابين الحبييات عند حدودها الخارجية لتعطي خطوط مسننة تمتد مستمرة على طول هذه السطوح تعرف بخطوط الستايلولايت (Stylolite).

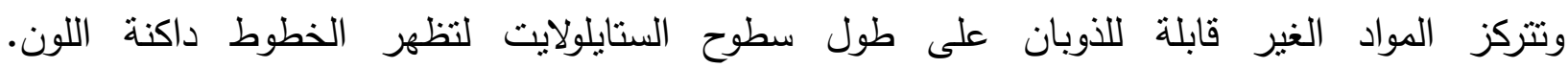
ويشير(Boggs, 2006) الى أن سطوح الإذابة تتتج غالباً بفعل الأجهادات التكتونية أو الدفن العميق.

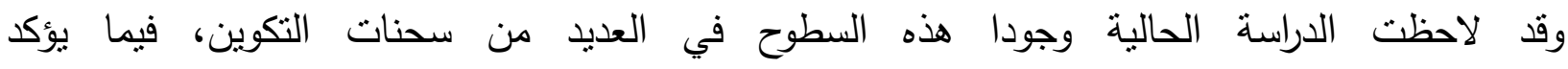
(Bathurst, 1975) على تقليل المسامية فضلاً عن تقليل سمك الصخور الرسوبية.

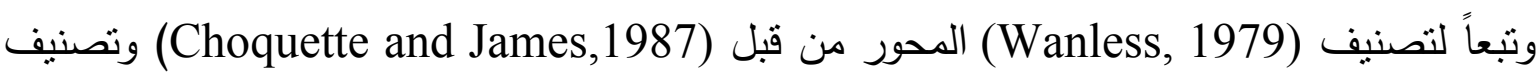
لسطوح الستايلولايت فقد تم تمييز ألأنواع التالية (Logan and Semeniuk, 1976 in Flugel, 2004)

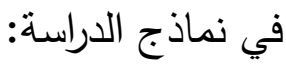

1-الستايلولايت الأملس Smooth stylolite: شكل هذا النوع يتميز بانحناته الواسعة ( لوحة 2-H).

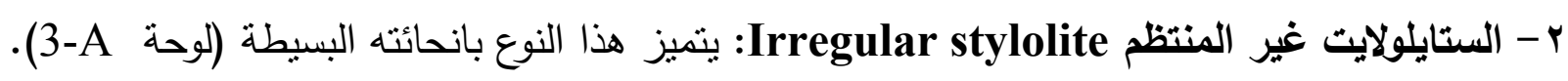

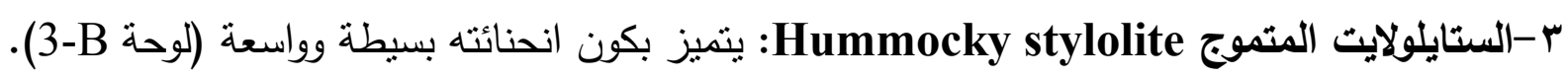

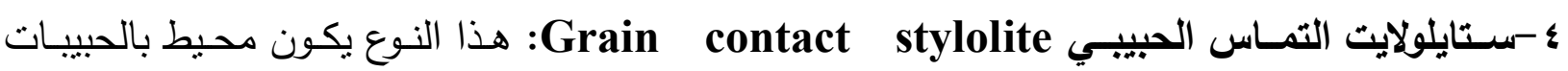


ه-الستايلولايت الموازي Parallel stylolite: نكون رقائق الستايلولايت منوازية وشبه مستقيمة

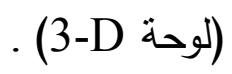

צ-الستايلولايت المتعدد الحبيبات Multi grain stylolite: هذه النوعية يكون سطح الستايلولايت يحيط اكثر من حبيبة (لوحة E-E).

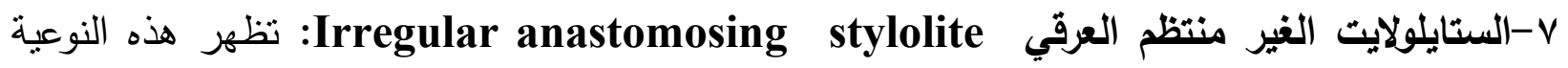
بشكل خطوط غير منتظمة ومتصلة مع بعضها (لوحة 3-F).

:Authigenesis تكوين المعادن موضعية النشأة -H

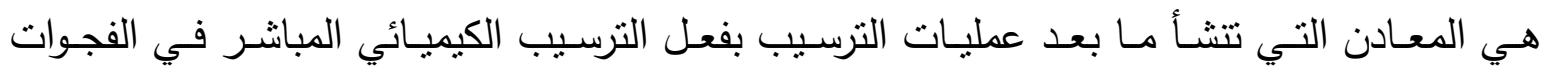
والفراغات أو بفعل عمليات أحلال محل معادن سابقة التكوين. ويعد معدن البايرايت أهم المعادن الموضعية النشأة المسجل في الدراسة الحالية. اذ تنتشر حبيبات معدن البايرايت بصورة مبعثرة ضمن الأرضية خصوصاً

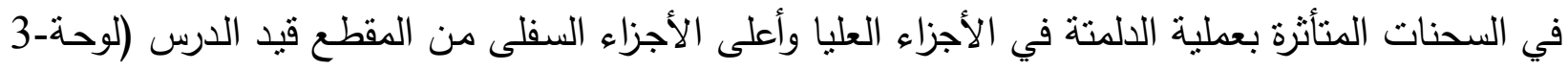

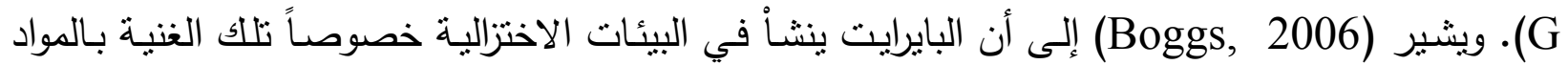
العضوية. ويعتق إن ترافق البايرايت مع الدولومايت ينتج عن استمرار العمليات التحويرية في ظروف بيئية خالية من الأوكسجين واختزال الكبريتات بساعد على حدوث تتويه للدولومايت ( Boeckelmann and .(Magaritz, 1991

\section{تعاقب العمليات التحويرية}

إن تفسير ومناقثنة ماذكر أعلاه من العمليات التحويرية قد أعطى معلومات لتوقيت العمليات التحويرية

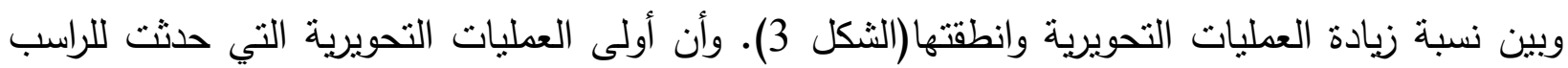

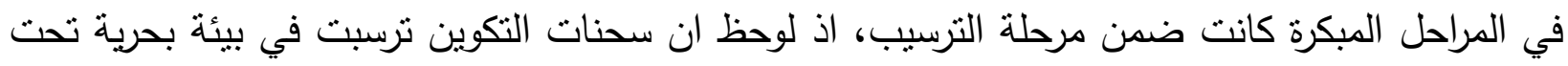

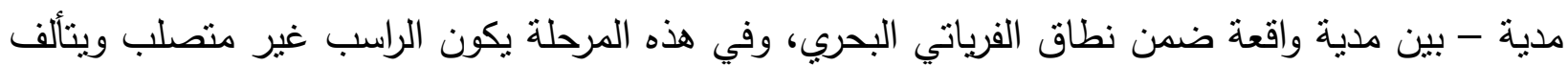
من حبييات الاركونايت والكالسايت عالي المغنيسيوم غير المستقر ، حيث أدت عملية الدكرتة الى تكوين غلاف مكرايتي حول الحبييات في السحنات ذات الدعم الطيني والسحنات ذات الدعم الحبيبي. أظهرت السحنات المترسبة في البيئة بين المدية تأثراً شديداً بعملية الدلمتة المبكرة، اذ امتازت دات دات هذاته السحنات بأحتوائها على حبييات الكوارتز الفتاتي المنقول من خارج حوض الترسيب واحتمال كونه مصدر

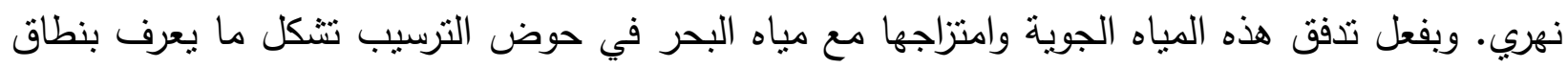
المزج، اذ تعرضت الروسب الواقعة تحت تأثثر هذا النطاق الى عملية الدلمتة. 
بعد طمر الراسب تحدث المرحلة التالية من العمليات التحويرية، اذ مع زيادة طمر الراسب تقل

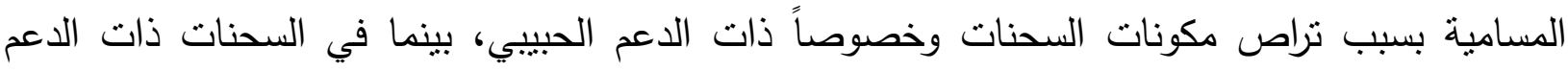

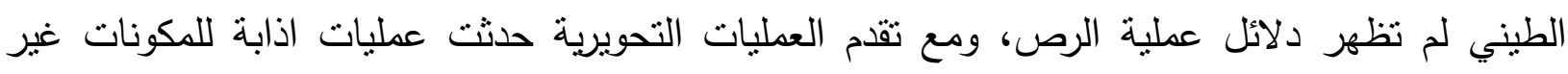
المستقرة مما يؤدي الى اغناء المحاليل بكاربونات الكالسيوم التي نساهم في عمليات السمنتة لاحقاً.

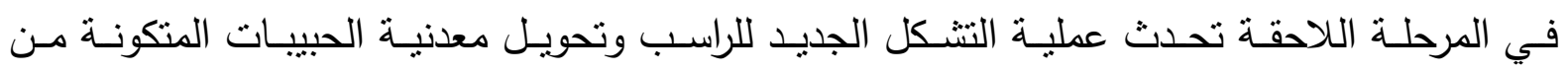

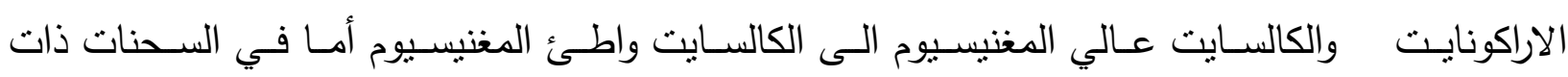

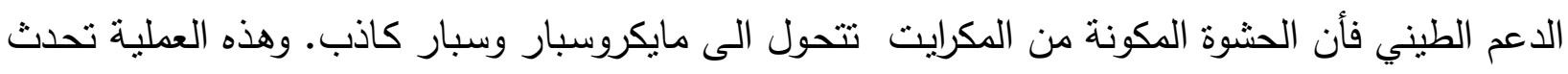
في بيئة جوية فرياتية ( Meteoric) (Matthews, 1966) إذ أن الزيادة في كمية كاربونات الكالسيوم

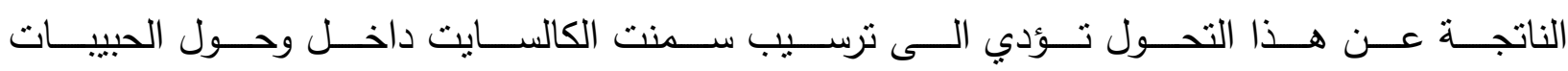
(Pingitore, 1970) تحدث في الجزء العلوي للدورات ( Topmost of cycles) وقد انشار نفس المصدر الى ان العوامل

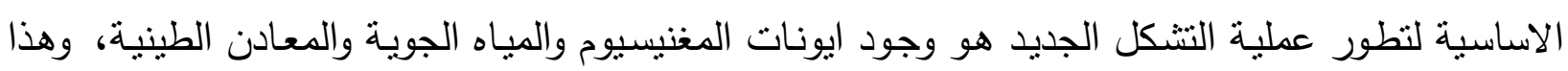

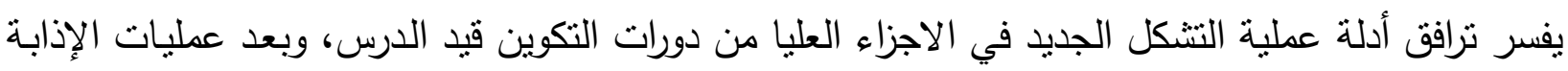

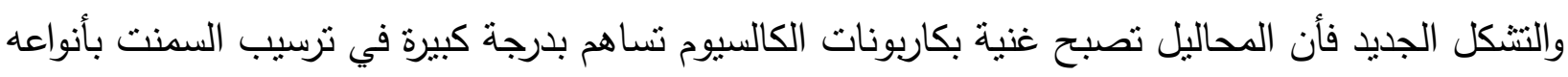

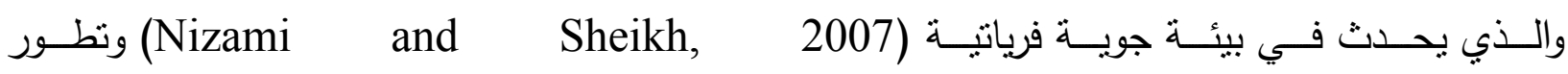

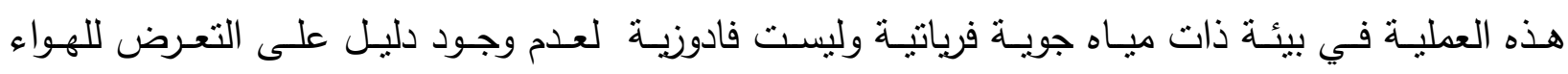

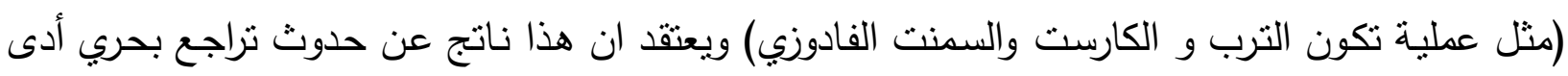

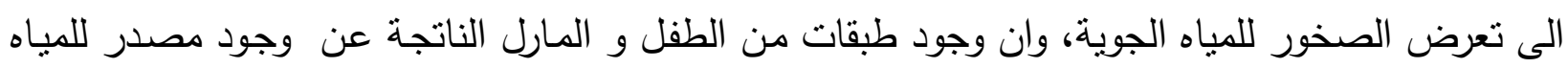

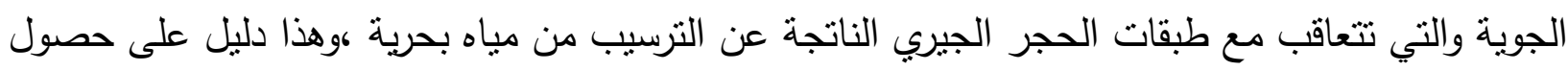

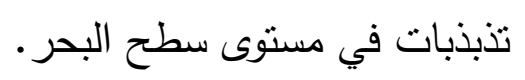
إن وجود التكسرات وخطوط الاذابة في بعض الحبيبات الهيكلية المتأثرة بعمليتي السمنتة أو التشكل

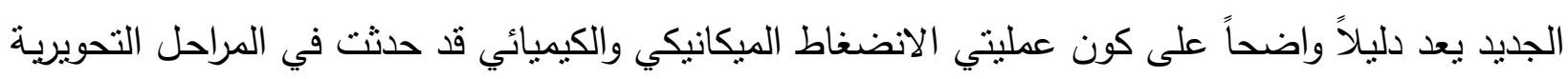
المتأخرة ( لوحة 3-B , 2-F)، اما الطور اللاحق للكسور فهي العملية التي تلت عملية الانضغاط الكيميائي

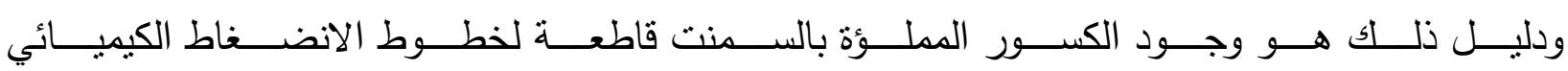




\begin{tabular}{|c|c|c|c|c|}
\hline $\begin{array}{c}\text { العمليات } \\
\text { التحويرية }\end{array}$ & $\begin{array}{c}\text { Micrite } \\
\text { envelope }\end{array}$ & Dolomitization & $\begin{array}{c}\text { Neomorphism, } \\
\text { Dissolution, } \\
\text { Cementation }\end{array}$ & $\begin{array}{c}\text { Physical and } \\
\text { Chemical } \\
\text { Compaction }\end{array}$ \\
\hline انطقه تحويرية & $\begin{array}{c}\text { Marine } \\
\text { phreatic }\end{array}$ & $\begin{array}{c}\text { Marine } \\
\text { Meteoric- mixed }\end{array}$ & $\begin{array}{c}\text { Meteoric } \\
\text { phreatic }\end{array}$ & Burial \\
& $\longrightarrow$ Time $\longrightarrow$
\end{tabular}

الثكل 3: مخطط يوضح انطقه العمليات التحويرية وتطورها مع الزمن.

\section{المصادر العربية}

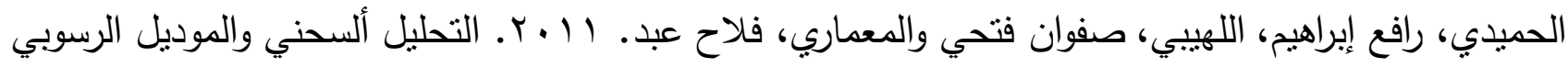
لتكوين خورمالة في منطقة دوكان-شمال شرق العراق. مجلة نكريت للعلوم الصرفة (تحت النشر ).

\section{المصادر الأجنبية}

Al-Qayim, B., 1995. Sedimentary Facies Anatomy of Khurmala Formation Northern Iraq, Iraqi. Geol. Jour.,Vol. 28, pp.36 - 46.

Al-Qayim, B., Al-Shibani, Sh., and Nisan, B. 1993. Stratigraphic Evolution of Paleogene Sequence, Haibat Sultan Northeastern Iraq .Iraqi. Geol. Jour. Vol. 21, pp. $51-65$.

Badiozamani, K., 1973. The Dorag Dolomitization Model - Application to the Middle Ordovician of Wisconsin. Jour. Sedimentary Petrology ,Vol. 43, pp. 965 - 984.

Bathurst, R. G. C., 1975. Carbonate Sediments and their Diagenesis, Development in Sedimentology. 12,2 ${ }^{\text {nd }}$. ed, Elsevier. Pub. Comp., 658 p.

Bellen, R. C. Van, Dunnington, H. V., Wetzel, R. and Morton, D. M. 1959. Lexique Stratigraphique International, ASIE, Vol. 111, Fascicule 10a, Iraq, $333 \mathrm{p}$. 


\section{صفوان فتحي اللهيبي}

Boeckelmann, K. and Magaritz, M. 1991. The Permian -Triassic of the Gartnerkofel-1 Core (Carnic Alps, Austria) . Dolomitization of the PermianTriassic sequence. Abhandlungen der Geologischen Bundesanstalt 45, pp. $61-68$.

Boggs, S. J. 2006. Principles of Sedimentology and Stratigraphy, Person PrenticHall, 662 p.

Bolton, C. M. G. 1958. Geological Map- Kurdistan Series, Scale 1. 10,000, Sheet k4, Ranya, Unpublished, Site Inves. Company Report, (276) SOM library, Baghdad.

Choquette, P.W. and Pray, L. C., 1970. Geologic Nomenclature and Classification of Porosity in Sedimentary Carbonates. Am. Assoc. Pet. Geol. Bull., Vol. 54, pp. $207-244$.

Choquette, P.W. and James, N. P., 1987. Diagensis in limestone: Part 3, The Deep Burial Environments. Geoscience Canada. Vol. 14, pp. 3 - 35.

Dunnington, H. V. 1958. Generation, Accumulation and Dissipation of Oil in Northern Iraq. In, L.G. Weeks (Ed.) Habitat of Oil. Am. Assoc. Pet. Geol. Bull., pp. 1194 - 1251.

Flugel, E., 2004. Microfacies of Carbonate Rocks , Analysis, Interpretation and Application. Springer Berlin Heidelberg New York, 976 p.

Heckel, P. H., 1983. Diagenetic Model for Carbonate Rocks in Mid - Continent Pennsylvanian Eustaticcyclothems. Jour. Sedimentary Petrology, Vol. 53, pp. 733 - 759.

Hsu, K. J., Siegenthaler, C., 1969. Preliminary Experiments on Hydrodynamic Movement Induced by Evaporation and their Bearing on the Dolomite Problem. Sedimentology, Vol. 12, pp. 11 - 25.

James, N. P. and Choquette, P. W., 1984. Diagenesis 9. limestones - The meteoric Diagenetic Environment: Geosci. Can., Vol. 11, pp. 161 - 194.

Jassim, S. Z. and Goff, J. C., 2006. Geology of Iraq. Published by Doline, Prague and Moravian Museum, Brno, 341 p.

Khalifa, M. A, 2005. Lithofacies, Diagenesis and Cyclicity of the 'Lower Member' of the Khuff Formation (Late Permian), Al Qasim Province 61- 6861- 68. Saudi Arabia Journal of Asian Earth Sciences, Vol. 25, pp. 719 - 734.

Longman, M. W. 1980. Carbonate Diagenatic Textures from Nearsurface Diagenatic Environments. Am. Assoc. Pet. Geol. Bull., Vol. 64, pp. 461 - 487. Machel, H. C, and Mountjoy, E. W. 1987. General Constraints on Expensive Pervasive Dolomitization and their Application to the Devonian Carbonate of Western Canada. Bull. Can. Pet. Geol., Vol. 35, pp. 143 - 158.

Matthews, R. K., 1966. Genesis of Recent lime Mud in Southern British Honduras: Jour. Sedimentary Petrology y, Vol. 36, pp. 428 - 454. 
Milliman, J. D., 1974. Marine Carbonates, Springer - Verlag, Berlin, 375 p.

Nizami, A, R. and Sheikh, R, A., 2007. Microfacies Analysis and Diagenetic

Settings of the Samana Suk Formation, ChichaliNala Section, Surgharrange,

Trans Indus ranges, Pakistan. Geol. Bull. PunjabUniv. Vol. 42, pp. 37 - 52.

Nizami, A ,R. and Sheikh, R, A., 2007. Microfacies Analysis and Diagenetic

Settings of the Samana Suk Formation,ChichaliNala Section ,Surgharrange,

Trans Indus Ranges, Pakistan . Geol. Bull. PunjabUniv. Vol. 42, pp. 37 - 52.

Pingitore, N. E., 1970. Diagenesis and Porosity Modification in Acroporapalmata.

Pleistocene of Barbados, West Indies: Jour. Sedimentary Petrology, Vol. 40, pp. $712-721$.

Randazzo, A. F. and Zachos, L. G., 1984. Classification and Description of

Dolomite Fabrics of Rocks from the Floridan Aquifer, U.S.A., Sedimentary Geology, Vol. 37, pp. 151 - 162.

Tucker, M. E. 1985. Sedimentary Petrology, an Introduction, $4^{\text {th }}$. Edition, Black Well Scientific Pub., 252 p.

Tucker, M. E., and Wright, V. P. 1990. Carbonate Sedimentology, Malden M A, Blackwell Publishing, $482 \mathrm{p}$.

Wanless, H. R., 1979. Limestone Response to Stress: Pressure Ssolution and dolomitization, Jour. Sedimentary Petrology, Vol. 49, pp. 437 - 462.

Zenger, D. H., 1983. Burial Dolomite in the lost Burro Formation (Devonian), East - Central California and the Significance of late Ddiagenesis Ddolomitization .Geology, Vol.11, pp. 519 - 522. 


\section{لوحة}
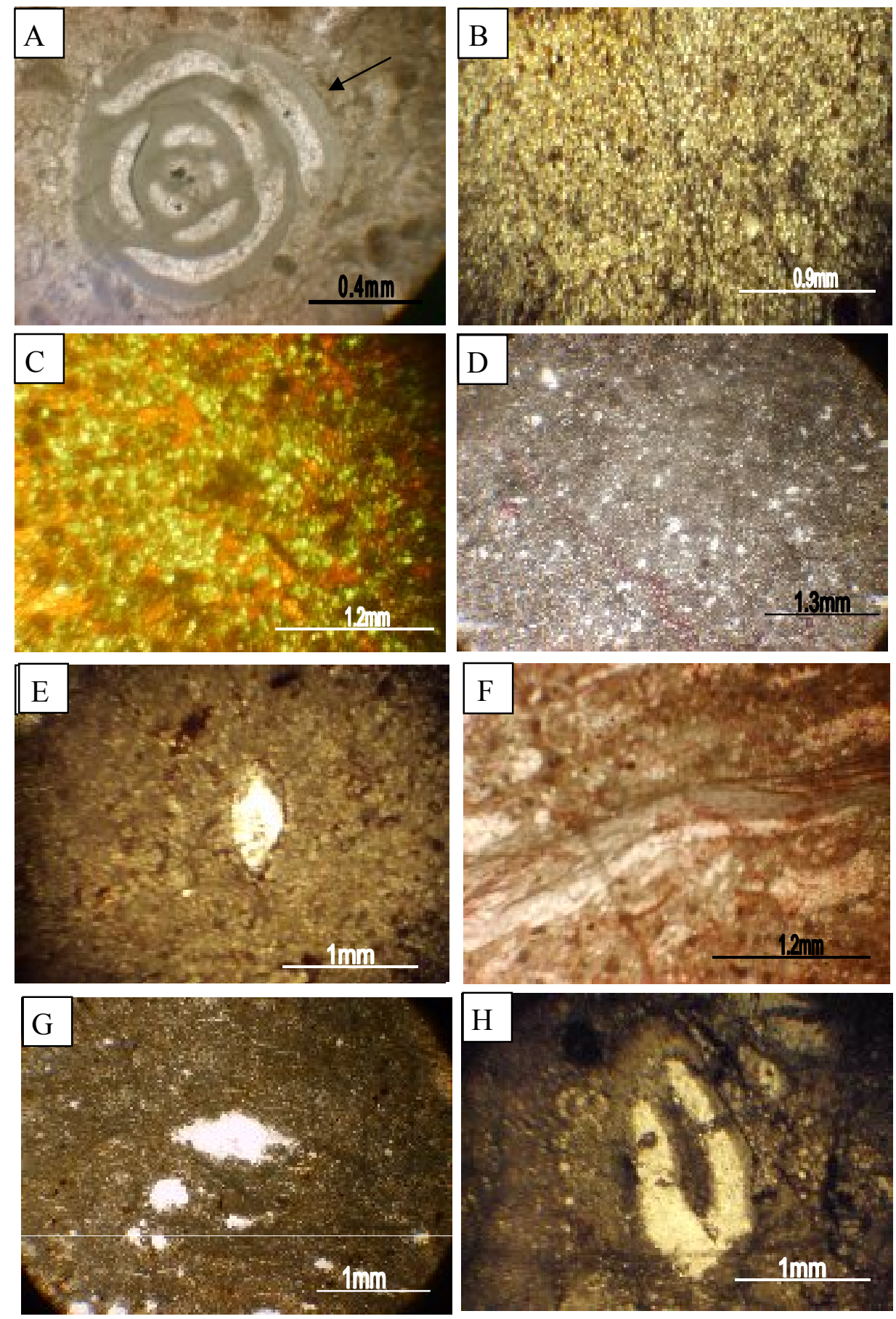

A- متحجر محاط بغلاف مكرايتي (السهم)، B- دولومايت ذو نسيج دقيق التحبب، C- دولومايت ذو نسيج موزائيكي درزي، D- دولومايت ذو نسيج موزائيكي منخلي، E- صدفة متحجر محاطة بغلاف مكرايتي

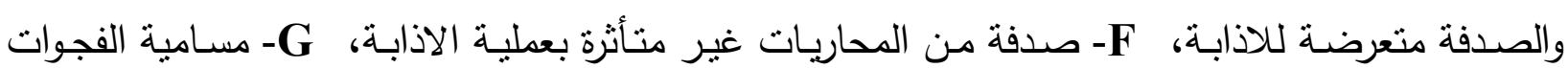
غيرالمنتظمة، H- مسامية قالبية ناتجة عن اذابة اصداف. 


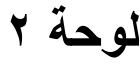
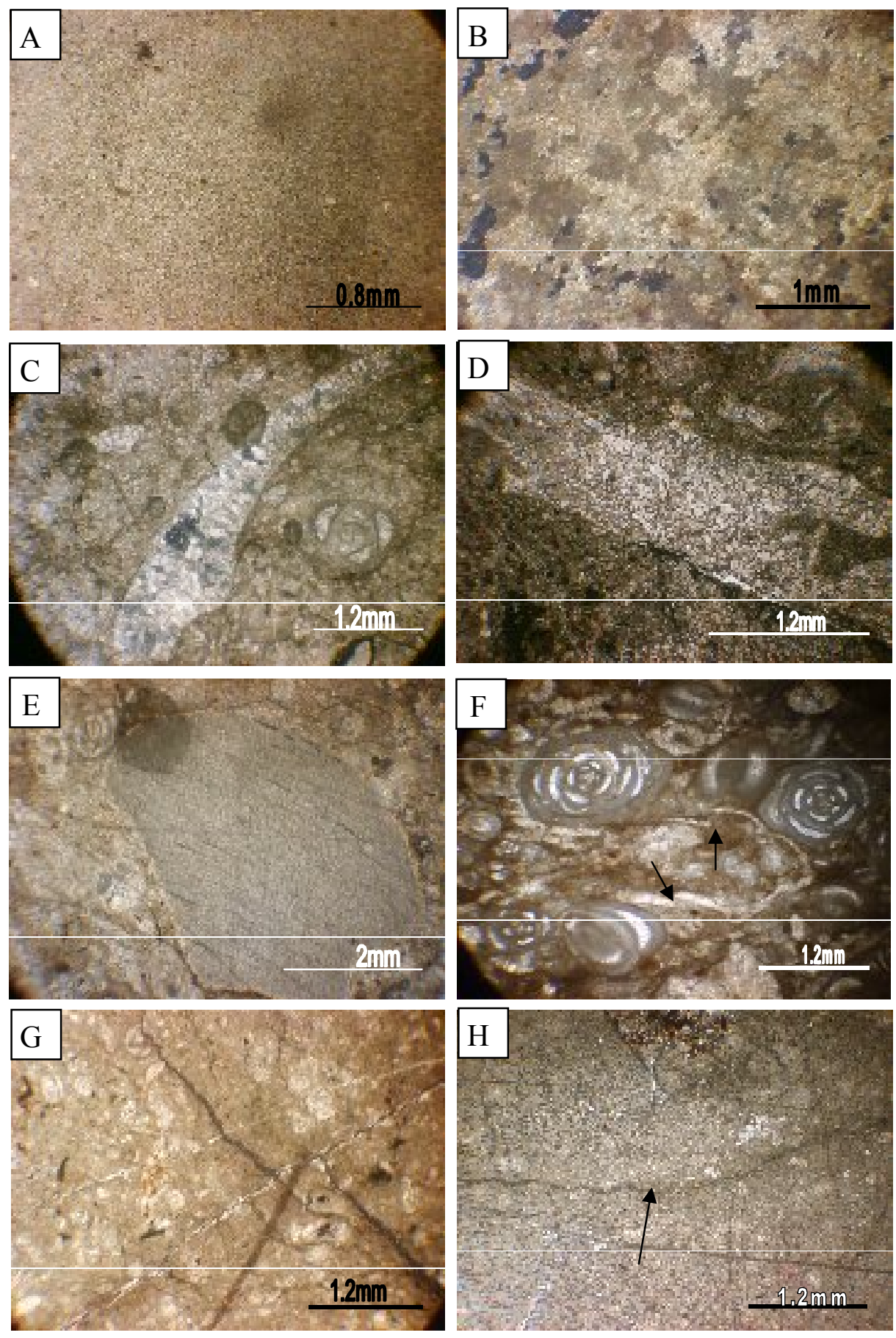

- A صورة توضـح السبار الدقيق، B- صورة توضـح السبار الكاذب، C- صدفة من فاسيات القدم متحولة

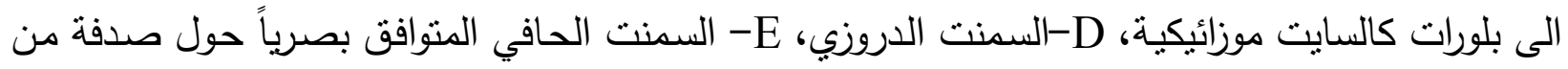

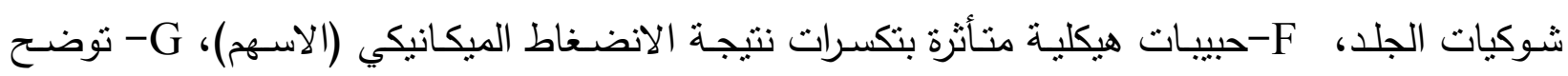
الكسور بأطوار مختلفة، H- ستايلولايت ملساء (السهر). 


\section{صفوان فتحي اللهيبي \\ لوحة ب}
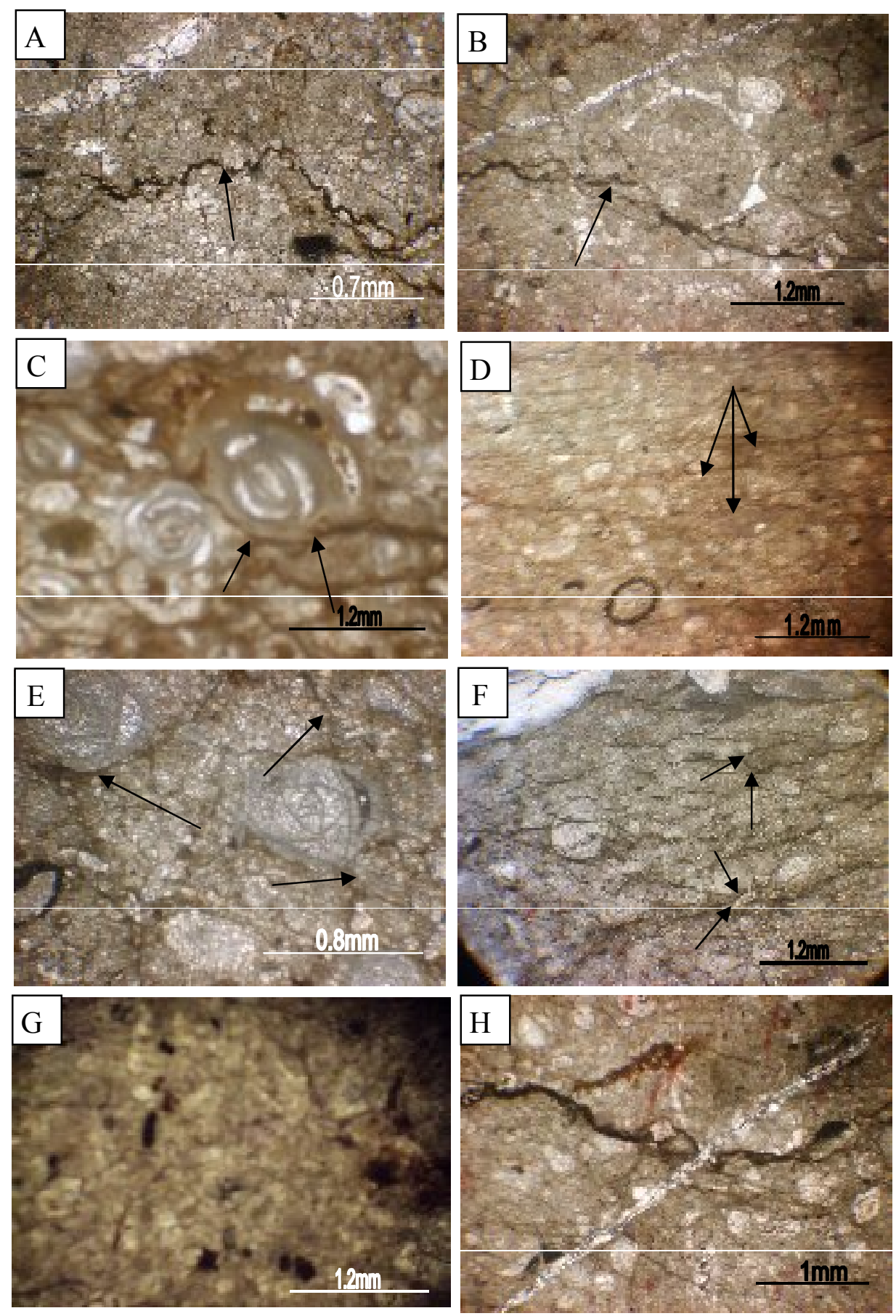

- A

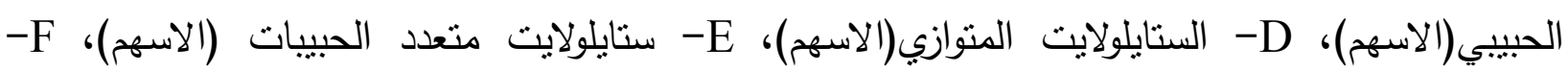

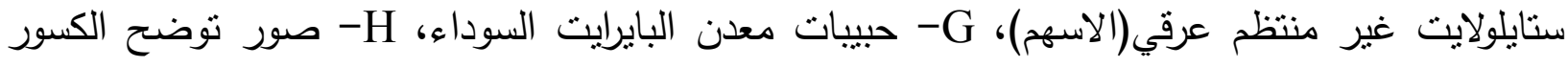
قاطعة لسطوح الاذابة ( الستايلولايت). 